\title{
Role of PRP in SNHL (Sensorineural Hearing Loss) in Children Less than 10 Years
}

\section{Brajpal Tyagi* and Manika Teotia}

Department of ENT, Harsh ENT Hospital, Ghaziabad, India

*Corresponding Author: Brajpal Tyagi, Department of ENT, Harsh ENT Hospital, Ghaziabad, India.
Received: October 11, 2021

Published: October 25, 2021

(C) All rights are reserved by Brajpal Tyagi.

\begin{abstract}
Introduction: Hearing loss is one of the common disabilities in India. The prevalence of this disability is higher in children. The children with sensorineural hearing loss is very common which requires the safe, natural, clinically effective and cost effective method of treatment.

Methods: The platelet rich plasma (PRP) was instilledintra tympanic in round window without piercing the round window membrane from BPST point [1]. 40 children of age less than 10 years and the hearing improvement was assessed by the BERA.

Results: It was found that $90 \%$ patients had bilateral impairment, and maximum patients were with moderate hearing impairment. The rate of improvement was found to be $82.5 \%$ except seven patient who had no improvement post PRP.

Conclusion: In our study, the patients with moderate to profound sensorineural hearing loss were found to have improved hearing after PRP treatment. Further studies with bigger sample size are needed to establish this method as new doorway for improving the childhood hearing.
\end{abstract}

Keywords: Sensorineural Hearing Loss; PRP; BERA

\section{Introduction}

Deafness or the hearing loss can be partial or total. The WHO definition of "deafness" refers to the complete loss of hearing ability in one or two ears. The cases include in this category will be those having hearing loss more than $90 \mathrm{~dB}$ in better ear (profound impairment) or total loss of hearing in both the ears. The WHO definition of "hearing impairment" refers to both complete and partial loss of ability to hear. In India, "hearing handicapped" as defined by the Rehabilitation Council of India Act., 1992, is - hearing impairment of $70 \mathrm{~dB}$ and above, in better ear or total loss of hearing in both ears. This law is applicable to only those persons with severe hearing impairment whose hearing loss is $70 \mathrm{~dB}$ and above [2-4].
In India, deafness is the most common disability accounting of more than 6.3 million sufferers. It has been estimated that four in every 1000 children suffer from severe to profound hearing loss. Around 100,000 babies are in-born with this disability. The estimated childhood onset deafness was found to be $2-4 \%[3,4]$.

Children with hearing loss cannot develop the speech and language abilities due to which affects their quality of life. The condition of these children gets worse in rural areas due to unavailability of medical facilities. Indian government has taken an initiative in this direction but the efforts are yet to provide the positive impact $[4,5]$. The level of hearing impairment is assessed with PTA/BERA [6-8]. 
Sensorineural hearing loss occurs due to obstructed transmission of stimuli to cochlea which may include air cells dysfunction or the eighth nerve itself. These patients perceive the sounds diminished and distorted [9].

The common symptoms of SNHL are plugged feeling or fullness of ear, tinnitus, vertigo, and hearing loss. The available pharmacological treatments options like antioxidant vitamins, coenzyme Q10 options are not curative but palliative only. Cochlear implants are helpful in the children below three years of age. And this technique is not cost effective in a country like ours [10].

Platelet rich plasma instillation therapy not only addresses the underlying cause but is also cost effective. Platelets play an important role in healing and enhancing the nerve cell growth through the growth factors and bioactive substances present in them. This amazing property of platelets has been utilized for treatment of olfactory dysfunctions, skin diseases, alopecia and in sensorineural hearing loss improvement [11]. Platelet rich plasma, also called autologous conditioned plasma, is the form of blood plasma, derived from whole blood, that has been enriched with platelets and growth factors [12]. Alpha granules and the dense granules contribute to the mechanism of action of platelet rich plasma. Alpha granules refers to the cluster of 7 growth factors which include; platelet-derived growth factors (PDG Faa, PDG Fbb and PDG Fab), transforming growth factor beta (isoforms TGF $\beta 1$ and 2); epithelial growth factor (EGF), and vascular endothelial growth factor (VEGF). Cell proliferation, cellular migration, differentiation angiogenesis and chemotaxis are the processes modulated by alpha granules. Dense granules basically contain bioactive agents (serotonin, histamine, dopamine, calcium and adenosine) which enhance the membrane permeability and modulate the inflammatory processes. Pre-packaged growth factors are released from these degranulated organelles. Due to short half-lives of these degranulated organelles, PRP need to be activated at or just before the application. This higher concentration of platelets followed by greater release of growth factors post initiation stimulates the cell proliferation and differentiation leading to the tissue regeneration $[12,13]$.

There is a need for the evaluation of technique of PRP in the treatment of SNHL.

This study was conducted to assess the PRP for the treatment of the SNHL in the children below the age of 10 years.

\section{Methods}

This study was conducted in a private clinical setting for a duration of one year. High risk neonates and children with delayed speech as well as language development were included in the study. The hearing loss and the degree of impairment was detected in the patients with Brain evoked response audiometry (BERA). Brain evoked response audiometry was done, in the dust free, soundproof, air-conditioned room. Half an hour before the beginning of BERA, GA was started in presence of anesthetist. The altered polarity with click sounds and stimulus of $11 / \mathrm{s}$ or $21 / \mathrm{s}$ was used. In the procedure, $110 \mathrm{~dB}$ sound pressure level was used as the threshold stimulus that was decreased gradually till the $V$ wave was just identifiable with satisfactory morphology. Absence of waves at $120 \mathrm{~dB}$ was considered as profound SNHL. The hearing sensitivity was assessed based of following [6].

\begin{tabular}{|l|c|}
\hline Hearing threshold & Sound pressure levels \\
\hline Normal hearing sensitivity & $\leq 25 \mathrm{~dB}$ \\
\hline Mild hearing impairment & $30-45 \mathrm{~dB}$ \\
\hline Moderate hearing impairment & $50-65 \mathrm{~dB}$ \\
\hline Severe hearing impairment & $70-85 \mathrm{~dB}$ \\
\hline Profound hearing impairment & $90 \mathrm{~dB}$ and above \\
\hline
\end{tabular}

Table 1: Hearing thresholds.

Based on initial BERA, 40 patients with sensorineural hearing loss (SNHL) and mixed hearing loss were selected.

Followed by this the intra tympanic PRP instillation was conducted. The time to draw the blood influences the clotting process. The whole blood sample was withdrawn with the large bore needle (18 no) by venipuncture method. This sample was taken in the vacutainer with the acid dextrose so as to prevent the early activation of the platelets. Then it was subjected to centrifugation using a soft spin at 1500 RPM. The supernatant plasma containing platelets was transferred into another sterile tube (without anticoagulant). This tube was centrifuged at a higher speed (a hard spin)3000 RPM to obtain the platelet concentrate. The lower $1 / 3^{\text {rd }}$ was PRP and upper $2 / 3^{\text {rd }}$ was platelet-poor-plasma (PPP). This PPP was removed, and the platelet pellets formed at the bottom of the tube were suspended in the minimum quantity of plasma $(2-4 \mathrm{~mL})$ by gentle shaking. 
Just before the injection PRP was activated exogenously by any of these; thrombin or calcium chloride or mechanical trauma. The patients received 3 injections per affected ear. Injection PRP was injected intratympanic in round window niches at BPST point [1] can be monitored with audiogram results each time patient reviewed. After injection patient was kept on antibiotics, antihistamines, and antacids and analgesics sos for a duration of five days. Injections were repeated every three weeks with BERA and compared with the previous BERA. Dexamethasone was used as the control in the study as it has been an established standard treatment [14].

The samples were assessed based on age, laterality of hearing loss (bilateral or unilateral), and type of hearing loss (conductive or sensorineural).

\section{Results}

In the present study, 40 children (age $<10$ years), with delayed speech and language development, were enrolled in the study. Bilateral impairment was found among $90 \%$ patients (Table 2). The average age was $3.84 \pm 2.46$ years.

\begin{tabular}{|l|c|}
\hline Hearing loss & n (percentage) \\
\hline Bilateral & $36(90 \%)$ \\
\hline Unilateral & $4(10.0 \%)$ \\
\hline
\end{tabular}

Table 2: Percentage of patients with Bilateral and Unilateral hearing loss.

Each of the moderate and severe impairment was found in both the ears in 18 patients. Profound impairment was reported in both the ears of 9patients and in right ear of 3 patient. Profound hearing impairment was found in left ear of 4 patients (Table 3 ).

\begin{tabular}{|l|c|c|c|}
\hline \multirow{2}{*}{$\begin{array}{l}\text { Ear with } \\
\text { impairment }\end{array}$} & \multicolumn{3}{|c|}{ V Wave } \\
\cline { 2 - 4 } & $\mathbf{< 7 0 ~ d B}$ & $\mathbf{7 0 - 9 0} \mathbf{~ d B}$ & $\mathbf{9 0 - 1 2 0 ~ d B}$ \\
\hline Both & 6 & 12 & 9 \\
\hline Left & 3 & 8 & 4 \\
\hline Right & 5 & 4 & 3 \\
\hline
\end{tabular}

Table 3: Patient distribution across different ranges of V Wave.

An average improvement of $25.59 \pm 24.25 \mathrm{~dB}$ was observed post PRP for both the ears with same hearing impairment. The left ear was with initial average hearing impairment of $94.25 \pm 15.42$ $\mathrm{dB}$ was found to have an average improvement of $26.25 \pm 25.29$ $\mathrm{dB}$ The right ear was with initial average hearing impairment of $91.62 \pm 22 \mathrm{~dB}$ was found to have an average improvement of 24.86 $\pm 23.38 \mathrm{~dB}$ (Table 4).

\begin{tabular}{|c|c|c|c|}
\hline $\begin{array}{l}\text { Ear with } \\
\text { impairment }\end{array}$ & $\begin{array}{c}\text { Initial PRP/ } \\
\text { BERA (dB) } \\
\text { (mean } \pm \text { SD) }\end{array}$ & $\begin{array}{c}\text { PTA/BERA post } \\
\text { PRP (dB) (mean } \\
\pm \text { SD) }\end{array}$ & $\begin{array}{c}\text { Improvement } \\
\text { post PRP }(\mathrm{dB}) \\
(\text { mean } \pm \mathrm{SD})^{*}\end{array}$ \\
\hline Both & $92.93 \pm 18.92$ & $75.72 \pm 22.24$ & $25.59 \pm 24.25$ \\
\hline Left & $94.25 \pm 15.42$ & $76.62 \pm 21.32$ & $26.25 \pm 25.29$ \\
\hline Right & $91.62 \pm 22$ & $74.72 \pm 23.48$ & $24.36 \pm 23.38$ \\
\hline
\end{tabular}

Table 4: Improvement post PRP.

$*$ it is the average of individual improvement recorded.

The overall data has been presented in the table 5 .

\section{Discussion}

Speech and language acquisition occur during first three years of life and auditory deprivation interferes with the neural structures which are responsible for hearing. If it is left undetected, it negatively affects the speech and language acquisition, academics achievements as well as the social and emotional development. These can be decreased or even prevented through early intervention. The incidence of hearing impairment in children as reported in different studies varies from 1-40\%. BERA is used for assessing the hearing impairment because results are not influenced by anesthetics and sedatives, cost-effective, and gives electrophysiological response of hearing without assessing the child behavior [15].

In the present study, 30(75\%) patients were below the age of five years, among these 30 patients, 6 were below the age of two years. In the study by Thakkar (2018) $80 \%$ of patients were in the age group of $0-5$ years and $20 \%$ aged 6 to 18 years [6].

In our study more maximum number of patients were found to have bilateral hearing impairment. Sudharahan Raj. C and Venkat Reddy. S (2016) conducted study on neonates and concluded that bilateral hearing impairment was more common than unilateral [14]. On initial examination it was found that maximum patients had moderate hearing loss which contributed to the delayed speech and language development. Thakkar (2018) reported that $40 \%$ of patients with decreased hearing showed profound hearing loss, 


\begin{tabular}{|c|c|c|c|c|}
\hline S. No. & Age & $\begin{array}{l}\text { Initial PTA/BERA } \\
\text { (V WAVE) }\end{array}$ & $\begin{array}{c}\text { AVG PTA / BERA (V WAVE) } \\
\text { After PRP }\end{array}$ & $\begin{array}{l}\text { INFERENCE (improvement/no } \\
\text { improvement) after } 3 \text { injections }\end{array}$ \\
\hline 1 & 5 months & $110 \mathrm{db}$ both ears & $80 \mathrm{db}$ both ears & Improved by $30 \mathrm{db}$ \\
\hline 2 & 8 months & $120 \mathrm{db}$ both ears & $120 \mathrm{db}$ both ear & No improvement \\
\hline 3 & 1 years & $120 \mathrm{db}$ both ears & $\begin{array}{l}\text { 80db in left ear and } 120 \mathrm{~dB} \text { in } \\
\text { right ear }\end{array}$ & $\begin{array}{c}\text { Improved by } 40 \mathrm{db} \text { in left and no improve- } \\
\text { ment in right ear }\end{array}$ \\
\hline 4 & 1 years & $100 \mathrm{db}$ both ears & $95 \mathrm{db}$ both ears & Improved by $5 \mathrm{db}$ \\
\hline 5 & 1.3 years & $90 \mathrm{db}$ both ears & $80 \mathrm{db}$ both ears & Improved by $10 \mathrm{db}$ \\
\hline 6 & 1.5 years & $110 \mathrm{db}$ both ears & $50 \mathrm{db}$ both ears & Improved by $60 \mathrm{db}$ \\
\hline 7 & 1.6 years & $100 \mathrm{db}$ both ears & $95 \mathrm{db}$ in both ears & Improved by $5 \mathrm{db}$ in both ears \\
\hline 8 & 1.7 years & $90 \mathrm{db}$ both ears & 70db Both ears & Improved by $20 \mathrm{db}$ \\
\hline 9 & 2 years & $95 \mathrm{db}$ both ears & $95 \mathrm{db}$ both ears & No improvement \\
\hline 10 & 2 years & $70 \mathrm{db}$ both ears & $50 \mathrm{db}$ both ears & improved by $20 \mathrm{db}$ \\
\hline 11 & 2 years & $\begin{array}{l}\text { 95db left ear } \\
\text { Right ear - normal hearing }\end{array}$ & $95 \mathrm{db}$ in left ear & No improvement \\
\hline 12 & 2 years & 110 in both ears & $110 \mathrm{db}$ in both ears & No improvement \\
\hline 13 & 2.3years & $90 \mathrm{db}$ both ears & $\begin{array}{l}75 \mathrm{db} \text { in right ear and } 80 \mathrm{db} \text { in } \\
\text { left ear }\end{array}$ & $\begin{array}{c}\text { Improved by } 15 \mathrm{db} \text { in right ear and by } 10 \mathrm{db} \\
\text { in left ear }\end{array}$ \\
\hline 14 & 2.5 years & $90 \mathrm{db}$ both ears & $70 \mathrm{db}$ both ears & improved by $20 \mathrm{db}$ \\
\hline 15 & 2.5 years & $100 \mathrm{db}$ both ears & $100 \mathrm{db}$ both ears & No improvement \\
\hline 16 & 2.5years & $100 \mathrm{db}$ both ears & $\begin{array}{l}\text { 90db in right ear and 95db in } \\
\text { left ear }\end{array}$ & $\begin{array}{l}\text { Improved by } 10 \mathrm{db} \text { in right ear and } 5 \mathrm{db} \text { in } \\
\text { left ear }\end{array}$ \\
\hline 17 & 2.9 & $100 \mathrm{db}$ both ears & $\begin{array}{c}\text { 85db in Right ear and 95db in } \\
\text { left ear }\end{array}$ & $\begin{array}{c}\text { Improved by } 15 \mathrm{db} \text { in right ear and } 5 \mathrm{db} \text { in } \\
\text { left ear }\end{array}$ \\
\hline 18 & 3 years & $110 \mathrm{db}$ both ears & $\begin{array}{c}\text { 70db left ear and 90db right } \\
\text { ear }\end{array}$ & $\begin{array}{c}\text { improved by } 40 \mathrm{db} \text { in left ear and } 20 \mathrm{db} \text { in } \\
\text { right ear }\end{array}$ \\
\hline 19 & 3 years & $100 \mathrm{db}$ both ears & $50 \mathrm{db}$ both ears & Improved by $50 \mathrm{db}$ \\
\hline 20 & 3 years & $100 \mathrm{db}$ both ears & $\begin{array}{l}\text { 80db in right ear and 95db in } \\
\text { left ear }\end{array}$ & $\begin{array}{l}\text { Improved by } 20 \mathrm{db} \text { in right ear and } 5 \mathrm{db} \text { in } \\
\text { left ear }\end{array}$ \\
\hline 21 & 3.5 years & $\begin{array}{l}90 \mathrm{db} \text { both ears (right ear } \\
\text { post cochlear implant) }\end{array}$ & $\begin{array}{c}70 \mathrm{db} \text { left ear and } 90 \mathrm{db} \text { right } \\
\text { Ear }\end{array}$ & improved by $20 \mathrm{db}$ in left ear only \\
\hline 22 & 3.5 years & $\begin{array}{l}50 \mathrm{db} \text { in left ear and } 90 \mathrm{db} \\
\text { in right ear }\end{array}$ & $\begin{array}{l}40 \mathrm{db} \text { left ear and } 60 \mathrm{db} \text { right } \\
\text { ear }\end{array}$ & $\begin{array}{l}\text { Improved by } 10 \mathrm{db} \text { left ear and no } 30 \mathrm{db} \text { in } \\
\text { right ear }\end{array}$ \\
\hline 23 & 4 years & $50 \mathrm{db}$ both ears & $30 \mathrm{db}$ in both ears & Improved by $20 \mathrm{db}$ in both ears \\
\hline 24 & 4 years & $90 \mathrm{db}$ both ears & $\begin{array}{l}\text { 85db left ear and } 50 \mathrm{db} \text { in } \\
\text { right ear }\end{array}$ & $\begin{array}{c}\text { Improved by } 5 \mathrm{db} \text { in left and } 40 \mathrm{db} \text { in right } \\
\text { ear }\end{array}$ \\
\hline 25 & 4 years & $70 \mathrm{db}$ both ears & $50 \mathrm{db}$ both ears & Improved by $20 \mathrm{db}$ both \\
\hline 26 & 4 years & $100 \mathrm{db}$ both ears & $95 \mathrm{db}$ both ears & Improved by $5 \mathrm{db}$ both ears \\
\hline 27 & 4 years & $\begin{array}{l}\text { 70db in right ear and } 80 \mathrm{db} \\
\text { in left ear }\end{array}$ & $\begin{array}{l}65 \mathrm{db} \text { in right ear and } 70 \mathrm{db} \text { in } \\
\text { left ear }\end{array}$ & $\begin{array}{c}\text { Improved by } 5 \mathrm{db} \text { in right ear and } 10 \mathrm{db} \text { in } \\
\text { left ear }\end{array}$ \\
\hline 28 & 4.5 years & $100 \mathrm{db}$ both ears & 95db both ears & Improved by $5 \mathrm{db}$ in both ears \\
\hline 29 & 4.5years & $100 \mathrm{db}$ both ears & $80 \mathrm{db}$ in both ears & Improved by $20 \mathrm{db}$ in both ears \\
\hline
\end{tabular}




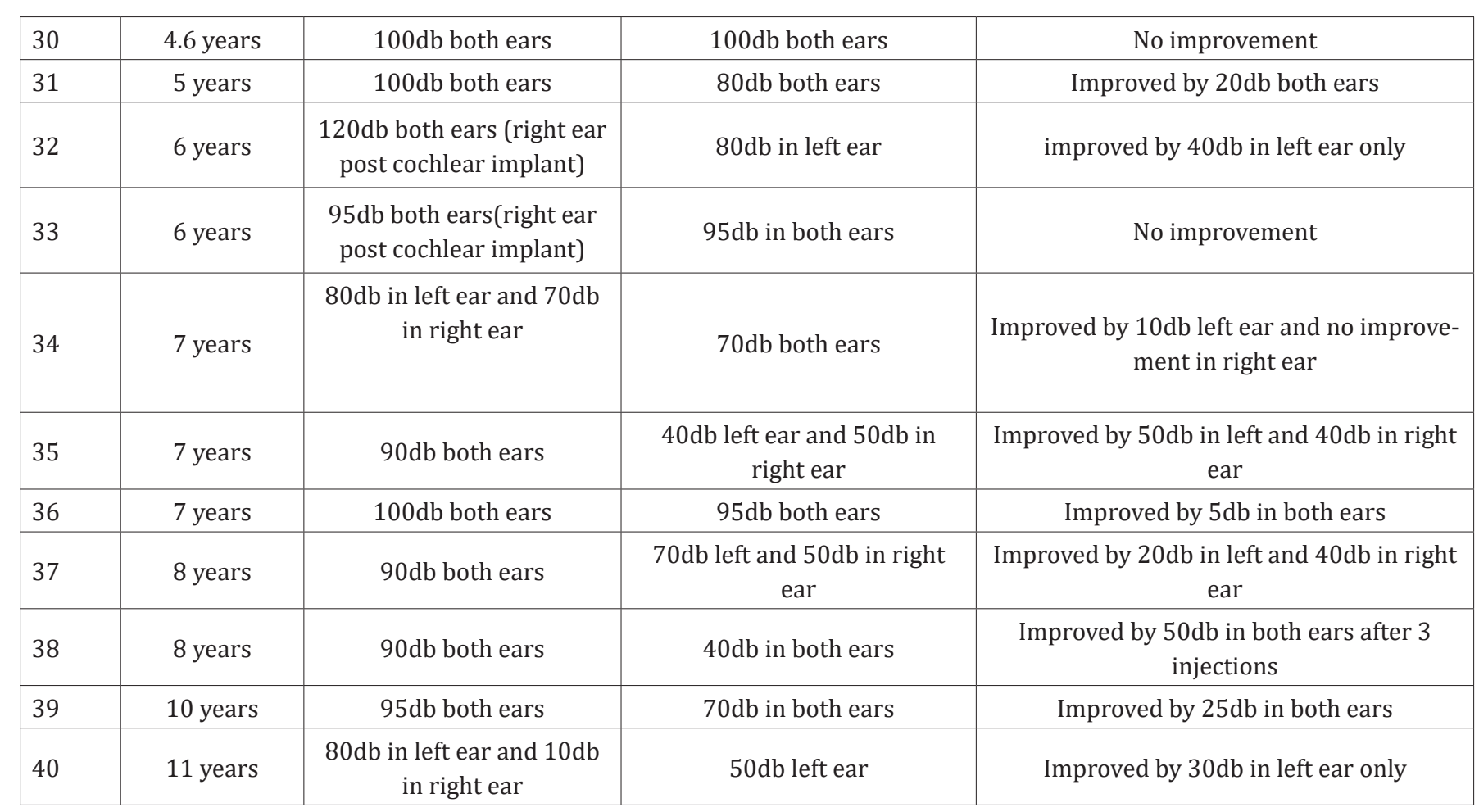

Table 5: Overall data presentation.

$40 \%$ showed severe hearing loss, and 20\% showed mild-to-moderate hearing loss [6].

After instillation of PRP, an average improvement of $25.59 \pm$ $24.25 \mathrm{~dB}$ was found in the patients with hearing impairment in both the ears. In patients with more impairment in left ear were reported to have an improvement of $26.25 \pm 25.29 \mathrm{~dB}$ while this improvement for right ear impairment was recorded as $24.86 \pm$ 23.38dB. This enhancement in the hearing level lead to the improvement in the speech discrimination level. In our study the overall hearing improvement rate was $82.5 \%$ as seven patients were found to have no improvement in the hearing after instillation of PRP. Yi Qian et.al. in the study of 75 children with SNHL, reported the overall recovery rate of $70 \%$ while using intratympanic methylprednisolone and compound betamethasone injected post auricularly [16].

\section{Conclusion}

In our study, the patients with moderate to profound sensorineural hearing loss were found to have improved hearing levels af- ter PRP treatment which directly enhanced their speech discrimination levels. Further studies with bigger sample size are needed to establish this method as new doorway for improving the childhood hearing.

\section{Bibliography}

\section{Volume 3 Issue 11 November 2021 \\ (C) All rights are reserved by Brajpal Tyagi.}

